\title{
Duchenne muscular dystrophy in one of monozygotic twin girls
}

J BURN*, S POVEY,+ Y BOYD AND D THOMAS $\|$

From * the Department of Human Genetics, University of Newcastle upon Tyne; †MRC Human Biochemical Genetics Unit, University College London; $¥$ Genetics Laboratory, Department of Biochemistry, Oxford; $\S$ Genetics Unit, Institute of Child Health, London; and \|Department of Neurology, St Mary's Hospital, London.

SUMMARY Monozygotic twin girls are reported, one of whom has the typical clinical features of Duchenne muscular dystrophy despite a normal female karyotype. Although certain features of the biopsy were atypical, the clinical diagnosis was supported by persistent markedly raised blood creatine kinase levels and findings typical of DMD on electromyography and magnetic resonance spectroscopy.

Analysis of an $\mathrm{X}$ linked DNA polymorphism in 16 independent somatic cell hybrids made between cells derived from each girl and a mouse line suggest that in one twin only the maternal $\mathrm{X}$ chromosome is active, whereas in the other the active $\mathrm{X}$ was paternally derived. More data are needed to exclude sampling error. These preliminary experimental results support the hypothesis that both girls are heterozygous for Duchenne muscular dystrophy. $\mathrm{X}$ inactivation, by chance resulted in two contrasting cell masses with different active $\mathrm{X}$ chromosomes. This segregation was followed by, and may even have resulted in, twinning into a female pair, one normal and one witlo the full clinical features of the disease.

In 1977 Gomez et al ${ }^{1}$ reported pseudohypertrophic muscular dystrophy in one of monozygotic twin girls. In 1982 Pena et $a l^{2}$ published an abstract giving details of a similar family. In both families there was a history of Duchenne muscular dystrophy. In the first report the unaffected twin had a raised serum creatine kinase level. In the second the clinically normal monozygotic twin sister of the proband gave birth to an affected son. These observations support the contention that such cases arise as a result of an unusual pattern of $\mathrm{X}$ chromosome inactivation producing one female in whom nearly all cells expressed the $\mathrm{X}$ chromosome with the Duchenne gene.

We report a further case of Duchenne-like, rapidly progressive, pseudohypertrophic muscular dystrophy in one of monozygotic twin girls and extend the hypothesis to suggest that the segregation of cells on the basis of $\mathrm{X}$ inactivation might actually have caused monozygotic twinning. Preliminary studies to identify the active $X$ chromosome in the two girls using mouse-human hybrids are presented.

Received for publication 23 May 1986.

Revised version accepted for publication 25 July 1986
These support the hypothesis and make it likely that the twin pair will be of considerable value in the search for the genetic and cellular basis of Duchenne muscular dystrophy.

\section{Case report}

The proband and her twin sister were born on 11.2.73 to an unrelated European couple. The mother was 27 years of age and the father was 26 years of age at the birth. The mother was aware of strong fetal movement during the pregnancy but at delivery the proband was noted to be a little floppy compared to the second born twin. The proband was recorded to weigh $2.22 \mathrm{~kg}$ whereas the subsequent normal twin was $2.39 \mathrm{~kg}$. The placenta was reported to be single.

One older sib, a female, was healthy and there was no significant family history. The mother has no brothers. Early development was unremarkable and the twins were sufficiently similar for the mother to find it difficult to distinguish between them at times. The proband walked at 15 months, five months later than her twin, and was noted to fall more frequently 
in subsequent years. Her physical disability became more apparent in striking contrast to her twin sister who was chosen to represent her county as a gymnast, and the proband was noted to make somewhat slower progress in her schoolwork. The mother became increasingly concerned at the proband's waddling gait but was unable to obtain specialist assessment until 1981 when the girls were 8 years old.

Examination revealed a twin pair whose appearance was strongly suggestive of monozygosity (fig 1a). Subsequent detailed analysis of blood group, serum, and HLA polymorphisms confirmed this impression (table 1). Analysis of restriction fragment length polymorphisms (RFLPs) at seven loci mapped to the $\mathrm{X}$ chromosome short arm revealed no differences between the two girls. Both girls were found to have a normal $46, \mathrm{XX}$ female karyotype. The unaffected twin and her mother were clinically normal and had creatine kinase levels of $21.9 \mathrm{IU} / \mathrm{l}$ and 26.0 IU/1 respectively (normal $<70 \mathrm{IU} / \mathrm{l}$ ).

The proband had a pulse rate of 96 and a heart in sinus rhythm with normal heart sounds. She weighed $22 \mathrm{~kg}$ and was $120 \mathrm{~cm}$ in height. The normal twin weighed $23.5 \mathrm{~kg}$ and was $128 \mathrm{~cm}$ tall. On examination there was no ophthalmoplegia but there was mild bilateral facial weakness and grade 4 power in the trapezii and neck flexors. There was, minimal winging of the scapulae, mild weakness of elbow extension, but marked weakness of hip flexion and extension and of knee extension. She toe walked with an obvious waddle and Gower's sign was positive (fig 1b). Tone was normal and reflexes were elicitable though somewhat depressed. The plantar responses were flexor. There was no fas-

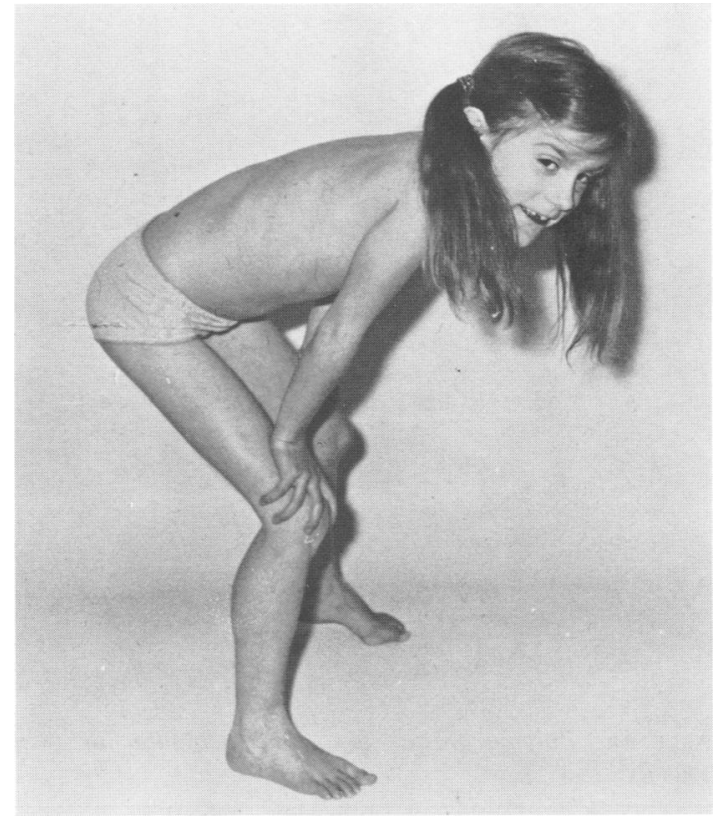

FIG 1 (b) Gower's sign: inability to rise from the floor without arm support.

ciculation and sensation was normal. Pseudohypertrophy of the calf muscles was evident (fig 1c).

Investigation showed a normal blood count, urea, and electrolytes but a markedly raised creatine kinase level of $930 \mathrm{IU} / \mathrm{l}$ (laboratory reference range 10 to 70$)$. An electrocardiogram was considered normal.

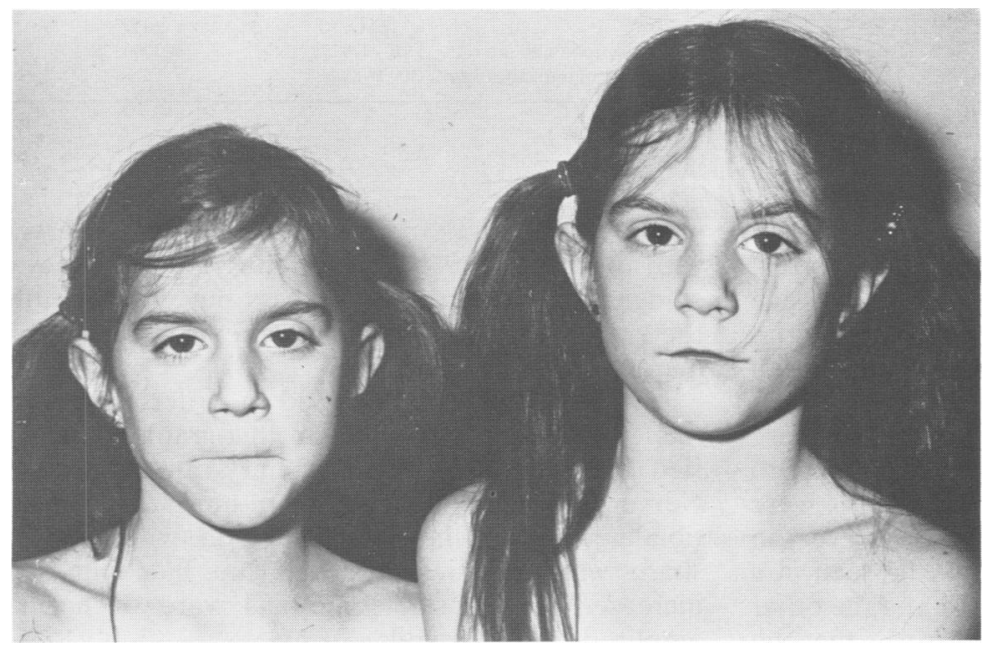

FIG 1 (a) Facial appearance of twins at 8 years. 


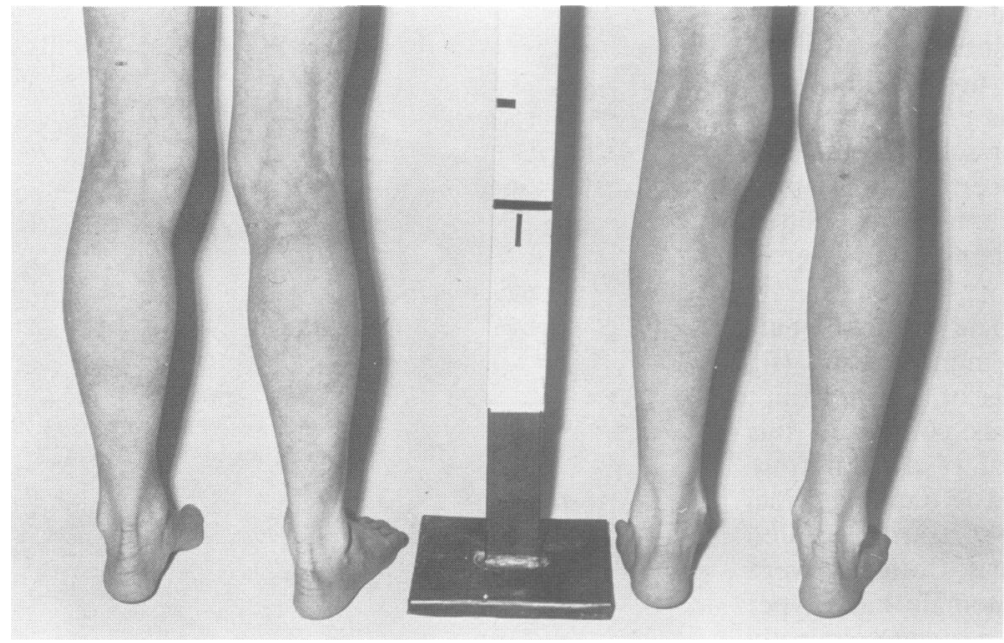

FIG 1 (c) Pseudohypertrophy of calves in affected twin on left. Normal twin on right.
TABLE 1a Polymorphisms used in calculation of twin zygosity.

\begin{tabular}{|c|c|c|c|c|}
\hline & Father & Mother & Twin 1 & Twin 2 \\
\hline 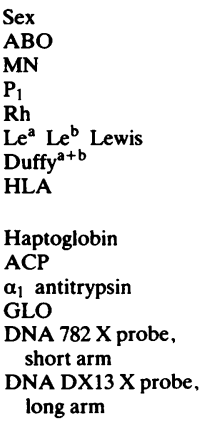 & $\begin{array}{l}\text { M } \\
\text { B } \\
\text { MN } \\
- \\
\text { rr } \\
-+ \\
++ \\
\text { A2 B21 } \\
\text { A1 B8 } \\
2-2 \\
\text { CB } \\
M_{1} S \\
2-1\end{array}$ & $\begin{array}{l}\mathbf{F} \\
\mathrm{A}_{1} \\
\mathbf{N} \\
+ \\
\mathrm{R}_{1} \mathbf{R}_{2} \\
-+ \\
+- \\
\mathrm{A} 25 \mathrm{~B} 40 \\
\mathrm{~A} 2 \mathrm{~B} 17 \\
2-1 \\
\mathrm{~B} \\
\mathrm{M}_{1} \\
2 \\
\\
2-1\end{array}$ & $\begin{array}{l}\mathrm{F} \\
\mathrm{A}_{1} \mathrm{~B} \\
\mathrm{~N} \\
+ \\
\mathrm{R}_{1} \mathrm{r} \\
+- \\
++ \\
\mathrm{A} 2 \mathrm{~B} 21 \\
\mathrm{~A} 25 \quad \mathrm{~B} 40 \\
2-1 \\
\mathrm{~B} \\
\mathrm{M}_{1} \\
2-1\end{array}$ & $\begin{array}{l}\mathbf{F} \\
A_{1} B \\
N \\
+ \\
R_{1} r \\
+- \\
++ \\
\text { A2 B21 } \\
A 25 B 40 \\
2-1 \\
B \\
M_{1} \\
2-1\end{array}$ \\
\hline
\end{tabular}

An open biopsy of the left quadriceps was performed which was initially accepted as being the picture of DMD. Examination by other authorities disputed this and proposed an atypical spinal muscular atrophy. Fig 2 illustrates some of the features. There was loss of normal architecture and excessive connective tissue. There was also enormous variation in fibre size with some fibres up to $200 \mathrm{mu}$ in diameter, a few hyaline fibres, but relatively little active necrosis or regeneration. Many of these normal, surviving, rather large fibres were found to be grouped together and the atrophied fibres were also clustered. These were embedded, however, in far more connective tissue than would be seen in a typical case of spinal muscular atrophy and the other important feature against this diagnosis was that the
TABLE 1b Calculation of probability of monozygosity.

\begin{tabular}{lll}
\hline & $M Z$ & $D Z$ \\
\hline Prior probability & 0.35 & 0.65 \\
Conditional probabilities & & \\
Sex & 0.5 & 0.25 \\
ABO & 0.29379 & 0.086313 \\
MN & 0.5 & 0.25 \\
P & 0.6850 & 0.4692 \\
Rh & 0.5 & 0.25 \\
Lewis & 0.25 & 0.0625 \\
Duffy & 0.5 & 0.25 \\
Hp & 0.5 & 0.25 \\
ACP & 0.5 & 0.25 \\
a1AT & 0.5 & 0.25 \\
GLO & 0.5 & 0.25 \\
HLA & 0.25 & 0.0625 \\
DNA probes & & 0.25 \\
Xp-782 & 0.5 & 0.25 \\
Xq-DX13 & 0.5 & $9.8068298 \times 10^{-11}$ \\
Joint probabilities & $4.3 \times 10^{-6}$ & pDZ \\
Posterior probabilities & 0.9999772 & 0.0000228 \\
Probability of monozygosity & $99.998 \%$ & \\
\hline
\end{tabular}

normal checkerboard appearance was preserved with no fibre type grouping. Thus, the biopsy was evidence of a dystrophic process but did not fulfil the criteria for typical Duchenne dystrophy in a male.

Investigations were pursued in order to resolve this difficulty. Detailed electromyography was carried out which confirmed primary muscle disease. Nerve conduction velocities were normal. The right tibialis anterior showed fibrillation with positive sharp waves, increased jitter and blocking, and increased polyphasia. Potentials were of normal amplitude, but of spiky form. 


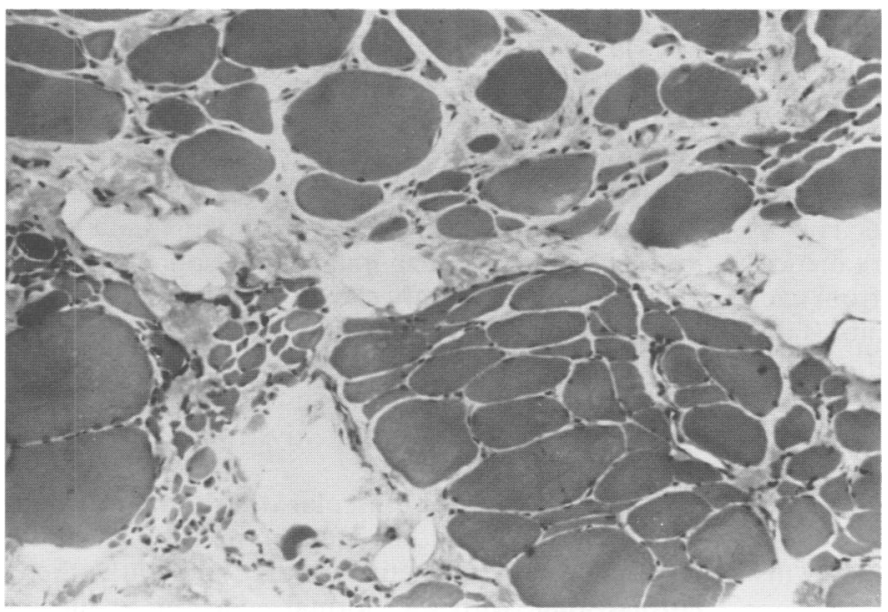

FIG 2 Muscle biopsy showing loss of normal architecture and excessive connective tissue with marked variation in fibre size and a few hyaline fibres but little active necrosis or regeneration. Some areas show grouped atrophy (no fibre type grouping).

Magnetic resonance spectroscopy of the left leg of both twins was performed. Spectra from the resting calf of the proband in the region of the gastrocnemius exhibited features observed in boys with DMD. ${ }^{3}$ The affected twin had a fat:water ratio of $2: 1$ compared to the normal twin's ratio of $1: 1$, indicating fatty infiltration. Phosphocreatine levels were reduced, while the inorganic phosphate levels were high in comparison to adenine triphosphate. The intracellular $\mathrm{pH}$ of $7 \cdot 31$ was alkaline (normal value $7 \cdot 05$ ). The spectra measured from the resting calf of the normal twin possessed none of these features.

Clinical review at the age of 12 years 7 months showed loss of mobility. Even with two assistants she was unable to take more than a couple of short steps. Shortening of the tendo achilles, particularly on the right, prevented normal placement of the foot on the ground.

There was minimal facial weakness, and in the limbs and trunk highly selective muscle weakness typical of Duchenne muscular dystrophy was present. There was also severe weakness of neck flexion, latissimus dorsi, deltoids, biceps, triceps, and wrist extension with preservation of the other muscles below the elbow and of the serratus anterior. The rhomboids were very weak while the trapezius and sternomastoids were of intermediate strength. Wasting of the lower part of pectoralis major made it equal in size to the upper part.

In the lower limbs, all muscles acting at the hip were weak and the quadriceps were wasted and weak (MRC grade 4 minus) with better preservation of the hamstrings. Profound weakness of dorsiflexion and eversion of the feet was noted, with preservation of inversion and plantiflexion. The latter imbalance was associated with plantiflexion contractures which were worse on the right. Tendon reflexes were severely diminished in the affected muscles but preserved at the ankles. Hypertrophy of both calves and of the anterior tibialis was noted.

Psychological testing revealed a 14 point discrepancy between higher performance and verbal intelligence quotient (102 and 88) in the affected girl with a lower overall quotient than her twin (94 compared to 112).

Analysis of the electrocardiograph in the normal twin revealed the algebraic sum of R-S in $\mathrm{V}_{1}$ to be $-3 \cdot 0$ (well within the normal range for a child of 12 years) whereas the affected twin had an abnormal sum of $+1 \cdot 5$.

Somatic cell hybridisation techniques were used to look for non-random $\mathrm{X}$ inactivation in the twins. Skin fibroblasts from each girl were fused to the mouse cell line $\mathrm{RAG}^{4}$ which is deficient in hypoxanthine-guanine-phosphoribosyl transferase (HPRT), using polyethylene glycol and selection in HAT medium (hypoxanthine, aminopterin, and thymidine). ${ }^{5}$ All surviving hybrids must contain an active human $\mathrm{X}$ chromosome which carries the gene coding for HPRT. Other chromosomes including the inactive $X$ may be retained by chance but tend to be lost. DNA from hybrid clones was extracted, digested with EcoRI, and subjected to a Southern blotting technique. ${ }^{6}$ The DNA fragments were then hybridised to probe 782 , which maps to $\mathrm{Xp} 22,{ }^{7}$ and was kindly provided by Professor P Pearson. Study of DNA from lymphoblastoid lines derived from the twins showed them both to be heterozygous for a polymorphism defined by this probe and the restriction endonuclease EcoRI, the two alleles being represented by fragments of $14 \mathrm{~kb}$ and $7 \mathrm{~kb}$. The 
probe does not cross hybridise with the mouse. The hybrids were scored for the presence or absence of the different alleles of 782 ; a representative autoradiograph is shown in fig 3 . In 13 cases a single band was seen and in six cases with both bands one of the bands was clearly predominant. In one hybrid the two bands were of equal intensity. Having regard to the way in which the hybrids were made it was considered that at least eight hybrids from each twin represented independent fusion events (table 2 ). The results show clearly that each informative hybrid from the affected twin retained the $X$ chromosome carrying the $14 \mathrm{~kb}$ fragment, whereas all those from the normal twin retained the chromosome carrying the $7 \mathrm{~kb}$ fragment. The chromosome with the $14 \mathrm{~kb}$ marker was derived from the mother and was present in the older sister of the twins.

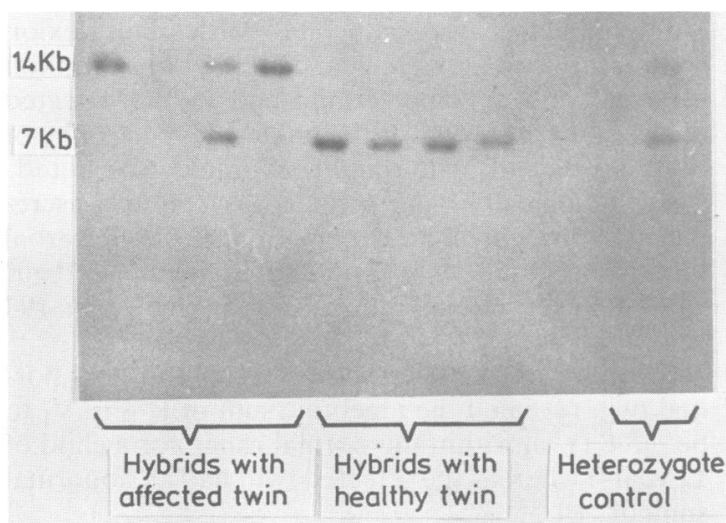

FIG 3 EcoRI digest from eight human-mouse hybrids and a human female heterozygote control, probed with the $X$ chromosome specific probe 782 (courtesy of Professor $P$ Pearson). Those clones, made with fibroblasts from the affected twin, which had a single $X$ chromosome produced only the $14 \mathrm{~kb}$ fragment. Clones with single bands from hybrids with the unaffected twin's cells produced the $7 \mathrm{~kb}$ fragment only (showed by family studies to be the paternally derived $X$ ).

TABLE 2 Analysis of DNA from independent hybrids between human fibroblasts and mouse cells from the RAG line deficient in HPRT.

\begin{tabular}{|c|c|c|c|c|c|}
\hline & \multicolumn{2}{|c|}{$\begin{array}{l}\text { Hybrid clones with } \\
\text { one X chromosome }\end{array}$} & \multicolumn{3}{|c|}{$\begin{array}{l}\text { Hybrid clones with } \\
\text { two X chromosomes }\end{array}$} \\
\hline & $X a$ & $X b$ & $X a>\quad X b$ & $X b>$ & $X a$ \\
\hline Affected twin & 3 & - & 5 & - & \\
\hline Normal twin & - & 7 & - & 1 & \\
\hline
\end{tabular}

\section{Discussion}

The clinical course and distribution of muscle weakness and pseudohypertrophy in the affected twin are typical of Duchenne muscular dystrophy. Despite the atypical biopsy features this diagnosis is further supported by the classic myopathic electromyogram, the nuclear magnetic resonance spectra results, ${ }^{3}$ and the highly characteristic impairment of verbal $\mathrm{IQ}^{8}{ }^{8}$

The algebraic sum of R-S in $V_{1}$ in the affected girl is outside the normal range and is a useful discriminant between a muscular dystrophy and spinal muscular atrophy. ${ }^{9}$

The occurrence of muscular dystrophy in females is attributed either to unequal lyonisation, such that a female carrier inactivates predominantly the $X$ chromosome with the normal gene, or to the girl suffering from the rare autosomal recessive form of the disorder. ${ }^{10}$ The presence of a clinically unaffected monozygotic twin sister effectively excludes the latter possibility. Two reasonable hypotheses may be proposed. The first is that $\mathrm{X}$ inactivation has occurred, such that by chance all of the cells which have inactivated the maternally derived $\mathrm{X}$ chromosome are clustered on one side of the zygote and 8 those using the paternally derived chromosome are on the other. The twinning process could then separate the two cell populations so that one twin? would be a manifesting female and the other a totally asymptomatic female carrier. The second possibility is that the zygote was initially genetically normal, but that after fertilisation a chromosomal deletion or translocation involving Xp21 ${ }^{11}$ occurred resulting in, again, a cell line of carrier cells with subsequent uneven lyonisation, causing a cluster of cells all using an $\mathrm{X}$ chromosome with the Duchenne type gene.

These two hypotheses would be open to examination if the girls were heterozygous for any expressed gene marker on the $\mathrm{X}$ chromosome, such as G6PD. In tiie first hypothesis the girls would be contrasting, with one of the alleles expressed in one girl and the other allele in her twin. In the mutation theory, again the affected twin would manifest a single allele, but the co-twin derived from the remaining mixture of cells should show the normal heterozygote pattern. Unfortunately, G6PD was not informative. $\mathrm{Xg}$ and testing for colour blindness also showed no difference between the twins. A direct use of the polymorphic DNA markers is not informative since digestion for this analysis includes the inactivated $\mathrm{X}$.

We have attempted to identify the active $X$ chromosome in a small sample of cells from each twin using the indirect approach of somatic cell 
hybrids. If it is accepted that the hybrid clones are independent and the results representative, the probability of the results we have obtained occurring by chance is extremely small $\left(1\right.$ in $\left.2^{15}\right)$. An unlikely possibility is that in each girl the biopsy may have hit a large patch of skin derived from a single cell line. Alternatively some selection may have occurred in the fibroblast cultures before the fusions. More hybrids are therefore being constructed using cells from different sites. Another possible approach to this problem would be combined investigation of polymorphism and methylation patterns in one of the heterozygous $\mathrm{X}$ linked loci. ${ }^{12}$ Further analysis is likely to provide information of value in the genetic counselling of the normal twin, who must be regarded as an obligate carrier on present evidence, and the older sister, who appears to have inherited from her mother the $\mathrm{X}$ chromosome which is active in the affected twin.

An important point of theoretical interest is the question of whether the twinning is regarded as a chance event or whether the separation was secondary to the establishment of two distinct cell populations. There is a persisting misconception that human twinning occurs normally at the two cell stage, whereas it is most likely that the two-thirds of monozygotic twin pairs which share placentae do so because twinning occurred after the chorion was defined. This would put it at the blastocyst stage, between the fourth and seventh days of gestation ${ }^{13}$ and potentially later than the time of lyonisation. Bocklage $^{13}$ points out that the idea of splitting the cell mass is probably incorrect and that the more likely event is developmental separation with two populations of cells forming distinct foci of development. This must be the case in monozygotic twinning before four days when the morula is confined within a rigid zona pellucida.

The proposal that unequal lyonisation could predispose to monozygotic twinning is attractive since it means that only one unusual event is postulated. In other words, in every female zygote which is a carrier of DMD there is a small but finite probability that lyonisation will occur in the way described, with the formation of distinct clusters of cells and a consequent predisposition to twinning. A similar explanation may be offered for the female twin pair described by Revesz et al ${ }^{14}$ in which one manifested the $\mathrm{X}$ linked factor IX deficiency (Christmas disease), though in this case the normal twin sister had a factor IX level in the heterozygote range.

This hypothesis may have more general application and in particular may be relevant to the not infrequent observation of monozygotic twins discordant for chromosome abnormalities such as Turner's syndrome. ${ }^{15}$ If 'unequal lyonisation' can lead to twinning in the absence of heterozygosity for a disease gene, this should be reflected in a female excess among monozygotic twins; it would represent a cause of twinning unique to female zygotes. While monozygotic twins in general do not show a significant preponderance of female pairs, it has long been recognised that conjoined twins, which are thought to result from very late twinning, are female in about $70 \%$ of cases. ${ }^{16}$

In conclusion, there is some difficulty in the diagnosis in these girls, and the evidence that the twins are inactivating different $\mathrm{X}$ chromosomes needs confirmation. The most likely interpretation, however, seems to be that both twins are heterozygotes for Duchenne muscular dystrophy and that manifestation in one twin is a result of non-random $\mathrm{X}$ inactivation. We feel that the potential research value of these twins merits publication at this stage. Fibroblasts and lymphoblastoid lines have been stored for research purposes. It has not escaped our notice that differences in the RNA produced in these lines might allow the identification of an expressed $\mathrm{X}$ linked sequence which might be a good candidate for the Duchenne muscular dystrophy gene.

The authors accept responsibility for any error or omission but wish to acknowledge the contribution of a great many colleagues. We are grateful to Professor John Edwards and Dr Michael Baraitser who stimulated the further investigation of this family. We thank Catherine Eldridge, Sheila Holt, and David Hunter for assistance with the RFLP and cytogenetic studies on the lympoid lines. This work was supported by the MRC (YB) and an award from the Muscular Dystrophy Group of Great Britain to Dr I W Craig (EM). During the early stages of this work JB was supported by an MRC project grant. The following clinicians and scientists, listed alphabetically, also gave valuable assistance; $\mathrm{Dr}$ Douglas Arnold, Dr Nicholas Cavanagh, Dr Kay Davies, Professor Alan Emery, Dr David GardnerMedwin, Dr Jon Jonasson, Professor Brian Lake, Dr John Morgan-Hughes, Professor Peter Pearson, Dr Ruth Sanger, Dr Doris Taylor, Dr Patricia Tippett, Sir John Walton, and Dr Jan Witkowski.

\footnotetext{
References

1 Gomez MR, Engel AG, Dewald GD, Peterson HA. Failure of inactivation of Duchenne dystrophy X-chromosome in one of femalc identical twins. Neurology (Minneap) 1977:27:537-41.

2 Pena SDJ, Karpati G, Carpenter S, Fraser FC. The clinical consequences of $\mathrm{X}$ chromosome inactivation: Duchenne muscular dystrophy in one of monozygotic twins. Neurology (Minneap) $1982 ; 32: 83 \mathrm{~A}$.

${ }^{3}$ Newman RJ, Bore PJ. Chan L, et al. Nuclear magnetic
} 
resonance studies of forearm muscle in Duchenne dystrophy. Br Med J 1982;284:1072-4.

${ }^{4}$ Klebe RJ, Chen T, Ruddle FH. Controlled production of proliferating somatic cell hybrids. J Cell Biol 1970;45:74-82.

5 Littlefield JW. Selection of hybrids from matings of fibroblasts in vitro and their presumed recombinants. Science 1964:145:709-10.

${ }^{6}$ Southern EM. Detection of specific sequences among DNA fragments separated by gel-electrophoresis. J Mol Biol 1975;98:503-17.

${ }^{7}$ Goodfellow PN, Davies KE, Ropers HH. Report of the committee on the genetic constitution of the $\mathrm{X}$ and $\mathrm{Y}$ chromosomes. Human Gene Mapping 8, 1985. Cytogenet Cell Genet 1985;40:296-352.

${ }^{8}$ Leibowitz D, Dubowitz V. Intellect and behaviour in Duchenne muscular dystrophy. Dev Med Child Neurol 1981;23:577-90.

${ }^{9}$ Emery AEH. Abnormalities of the electrocardiogram in hereditary myopathies. J Med Genet 1972;9:8-12.

10 Gardner-Medwin D, Johnson HM. Severe muscular dystrophy in girls. J Neurol Sci 1984;64:79-87.

11 Verellen-Dumoulin C, Freund M, DeMeyer R, et al. Expression of an $\mathrm{X}$ linked muscular dystrophy in a female due to translocation involving Xp21 and non-random inactivation of the normal X chromosome. Hum Genet 1984;67:115-9.
12 Vogelstein B, Fearon ER, Hamilton SR, Feinberg AP. Use of restriction fragment polymorphisms to determine the clonal origin of human tumors. Science 1985;227:642-5.

${ }^{13}$ Bocklage CE. On timing of monozygotic twinning events. In: Gedda L, Parisi P, Nance WE, eds. Twin biology and multiple pregnancy. New York: Alan $R$ Liss, 1981:155-65.

${ }^{14}$ Révész T, Schuler D, Goldschmidt B, Elödi S. Christmas disease in one of a pair of monozygotic twin girls, possibly the effect of Lyonization. J Med Genet 1972;9:396-400.

${ }^{15}$ Gilgenkrantz S, Marchal C, Wendremaire $P$, Seger $M$. Cytogenetic and antigenic studies in a pair of twins: a normal boy and a trisomic 21 girl with chimera. In: Gedda L, Parisi P, Nance WE eds. Twin biology and multiple pregnancy. New York: Alan R Liss, 1981:141-53.

${ }^{16}$ Benirschke K, Kim CK. Multiple pregnancy. $N$ Engl J Med 1973;288:1276-84,1329-36.

Correspondence and requests for reprints to $\operatorname{Dr} \mathbf{J}$ Burn, Department of Human Genetics, University of Newcastle upon Tyne, 19 Claremont Place, Newcastle upon Tyne NE2 4AA. 